\title{
CULTURAL DIFFERENCES IN PARENTAL ATTITUDES AND WAYS OF COPING TOWARDS LEARNING DISABILITIES \\ OF THEIR CHILDREN - AN OUTLINE OF A RESEARCH STUDY
}

\begin{abstract}
AвSTRACT. Gonen-Avital Shiri, Cultural Differences in Parental Attitudes and Ways of Coping Towards Learning Disabilities of their Children - An Outline of a Research Study [Różnice kulturowe w podejściu rodziców do trudności w uczeniu się ich dzieci oraz sposoby radzenia sobie z nimi - wprowadzenie do badania]. Studia Edukacyjne nr 48, 2018, Poznań 2018, pp. 401-409. Adam Mickiewicz University Press. ISSN 1233-6688. DOI: 10.14746/se.2018.48.27
\end{abstract}

The main aim of the article is to identify and explain the issues of parents' attitudes and ways of coping with their situation as parents toLearning Disability children, in relation to the differentCultural parents. This article stems from a deep and extensive dissertation research on parents' attitudes toward their child Learning Disability in Israel and it is presented as an outline of the research study. Studying the parents attitudes and coping with their child's Learning Disability, is an important area that should generate interest among researchers. The family is the source of the child's development, and the parents are responsible for the creation of his values and beliefs.

In summary, the connections between Learning disability, society and culture, attitudes, stress and coping concerning the parents of children diagnosed as having Learning was discussed in this article. There is an urgent need to explore these parents' varied cultures, their different beliefs, attitudes, and their characteristics. It is important to remember that the family is a supportive framework that protects the child. The best way to help the L.D. child and his family is through understanding the way in which they experience the disability at home, and in the community.

Key words: Parents, Learning Disability, Cultural Differences, Coping, Stress

\section{Introduction}

Today in the technological age, along with the cultural diversity in Israel and the growing trend of diagnosing more children as having Learning Disability, it is necessary to recognize the sociological motives, including the 
cultural differences within the parents of these children that ultimately may affect the quality of the plan care and support. The main aim of the article is to identify and explain the issues of parents' attitudes and ways of coping with their situation as parents to Learning Disability children, in relation to the different ethnic group of parents (Israeli natives, former USSR, Muslims and Ethiopia) This article stems from a deep and extensive dissertation research on parents' attitudes toward their child Learning Disability in Israel and it is presented as an outline of the research study.

The former article, ${ }^{16}$ focused on explaining the Learning Disability situation, and the Cultural Characteristic of the four main ethnic families in Israel. This article focus on the Israeli parents' attitudes and the ways of coping with their child who was diagnosed with learning disability, based on Hofstede's cultural dimensions. ${ }^{17}$ The author believes that understanding the sociologic factors (of each of the four main ethnic in Israel) that might serve as a basis to the parents's attitudes and ways of coping with, will help the caregivers and the authorities and give them better tools, how to achieve better outcomes for the benefit of the child, his parents and the whole community.

Intercultural learning is a topic which receives much interest due to the rise of cultural studies and globalization. Cultural differences in the learning processes is most important for the intercultural learning which focus on understanding the culture's effect of the families' approach to education in general and to special education in particular.

An American sociologist named Hofstede talks about cultural values. ${ }^{18}$ Values are actually how we learned to think about how things should be, or people should behave, especially in terms of features such as honesty, integrity, openness, etc. The values that exist in us can affect many of the judgments we make, as well as affect the support we give to others. Common values are those that are widely shared among a group, community, or culture. They are transmitted through sources such as media, institutions, religious or family organizations.

\section{Attitudes toward Learning Disability}

Attitudes can be defined as evaluations of ideas, events, objects, or people. Attitudes are generally positive or negative, but they can also be uncertain at

${ }^{16}$ S. Gonen-Avital, Cultural Diversity and its implication on parents' attitudes toward their child, Learning Disability, 2016.

${ }_{17}$ G. Hofstede, Dimensionalizing cultures: The Hofstede model in context, Online Readings in Psychology and Culture, 2011, 2(1), 8.

${ }^{18}$ G. Hofstede, Culture's consequences: Comparing values, behaviors, institutions and organizations across nations, Sage Publications, 2003. 
times. Chaiklin (2011), who has studied the relationship between attitudes, behavior and social practice, notes that as attitudes are important, and there will be no social justice without addressing greater attention to modify the behavior itself. Every attitude has three components that are represented in what is called the ABC model of attitudes: Affect, Behavior, and Cognitionare three components that have relationship between them. ${ }^{19}$ The connection between these three elements is significant, and a change in one of them, directly affects the others. According to Philipchalk ((1995, the study of the attitudes is critical, because attitudes' study results show how people feel, think and behave. Figure number 1 demonstrates the ABC Model.

1. Emotion (Affect) - an emotional response related to attitudes. Attitudes related to how much we like or dislike the subject of the attitudes.

2. Behavior: behavior is more likely to act in ways that are consistent with our attitudes.

3. Cognition: knowledge of the subject attitudes - beliefs, ideas, memories and pictures. These three ingredients may help in the analysis of attitudes - it seems that there are three inputs that influence the attitudes, so there are three possible sources of change in attitudes. In addition, it demonstrates that in order to make a change in attitudes, it requires a general change in behavior, cognition and emotion.

Dyson (2010) argues in her research that the presence of a child with learning disabilities, influence improperly on the family functioning and sibling. ${ }^{20}$ Various studies show that children diagnosed with learning disabilities are having few problems like: low self-esteem, anxiety, ${ }^{21}$ and from lower peer acceptance. ${ }^{22}$ The direct consequence of these problems is that they have an impact on parent's and sibling's attitudes and perceptions. Dyson, (1996) adds that the most prominent social problem related to learning disability, is that this problem is often invisible and it is characterized as a benign and simple problem. ${ }^{23}$ A study that was carried out in Israel, ${ }^{24}$ found that families with learning disabilities children, did not differ from nondisabled

19 R.P. Philipchalk, Invitation to social psychology, Harcourt Brace College Publishers, 1995, A.H. Eagly, S. Chaiken, The Psychology of Attitudes, Fort Worth, TX: Harcourt Brace Jovanovich, 1993.

${ }^{20}$ L. Dyson, Unanticipated effects of children with learning disabilities on their families, Learning Disability Quarterly, 2010, 33(1).

${ }^{21}$ W.S. Grolnick, R.M. Ryan, Self-Perceptions, Motivation, and Adjustment in Children with Learning Disabilities a Multiple Group Comparison Study, Journal of Learning Disabilities, 1990, 23(3).

${ }_{22}$ W.L. Stone, A.M. La Greca, The social status of children with learning disabilities: A reexamination, Journal of Learning Disabilities, 1990, 23(1).

${ }^{23}$ L.L. Dyson, The experiences of families of children with learning disabilities: Parental stress, family functioning, and sibling self-concept, Journal of Learning Disabilities, 1996, 29(3).

${ }_{24}$ T. Heiman, O. Berger, Parents of children with Asperger syndrome or with learning disabilities: Family environment and social support, Research in Developmental Disabilities, 2008, 29(4). 
families in terms of family relationships, cohesion, personal growth, or social support. Regarding expression of feeling, Margalit \& Heiman, (1986) found among families, with a child with L.D, less expression of feeling than in ordinary families. ${ }^{25}$

Therefore, when L.D is diagnosed, the child's parents may react with feelings of disappointment and frustration of the situation. They are angry because of the disappointment, sometimes there is a feeling of helplessness, self-pity, rejection and sense of guilt that may have been created due to a genetic reason.

The problems that the child and their parents may encounter in school might be: poor relationship between siblings, low self-esteem, difficulty in making social connections, and loneliness. Actually, the parents reactions can be affected by several factors such as: the degree of disorder visibility, whether this disability can affect negatively the attitudes of others.

\section{Culture diversity and parents attitudes}

Emphasizing the cultural aspect, while studying the behavior of parents on coping with their child's learning disability, is an important area that should generate interest among researchers. Actually, the person cultural background has a significant impact on attitudes toward learning disability. Desforges \& Abouchaar (2003) researched parents involvement, they claim that parental involvement is strongly influenced by family social class, deprivation, psycho-social health, level of education, single parent status and, also, by family ethnicity. ${ }^{26}$

According to Chandramuki \& Vranda (2012), every parent wants his child to be perfect in every way, and their disappointment with the discovery of disability can develop negative attitudes towards the child. ${ }^{27}$ They claims that in India, they perceive disability in concept of tragedy, therefore, these cultural beliefs play a role in the decision on how parents see their disability. That is why, differences between parents in their level of accepting the disability, is associated with culture diversity that is expressed in parents' beliefs, attitudes, social class, poverty, and more.

${ }^{25}$ M. Margalit, T. Heiman, Family climate and anxiety in families with learning disabled boys, Journal of the American Academy of Child Psychiatry, 1986, 25(6).

${ }^{26}$ C. Desforges, A. Abouchaar, The Impact of Parental Involvement, Parental Support and Family Education on Pupil Achievement and Adjustment: a Literature Review, 2003.

${ }^{27}$ S. Chandramuki, M.N. Vranda, Attitudes of parents towards children with Specific Learning Disabilities, Disability, CBR and Inclusive Development, 2012, 23(1). 


\section{Stress as cognitive process and coping with it}

Coping is an effort to solve personal and interpersonal problems, and a way of working toward, minimizing, or tolerating stress or conflict. ${ }^{28}$ The coping process include efforts to reduce perceived stress through a wide range of emotion, actions and thoughts, directed at both external stressors and internal demands and needs.

\section{Parents stress and coping}

Stress is the body's way of responding to any kind of demand. Stresses can be external (from the environment, psychological, or social situations) or internal (illness, or from a medical procedure). The reasons for the appearance of stress may differ as a result of interaction with people, situations and environment. ${ }^{29}$

The family is the source of the child's development, and is responsible for the creation of his values and beliefs. When the parents receive the diagnosis results confirming the learning disability of their child, they accept it with a sense of great loss. Parents find it difficult to assimilate the fact that their expectations are not going to be realized, sometimes they feel as if the role of parenting that they anticipated too much, was taken from them. After the initial shock of diagnosis, the parents' reaction are emerging in order to process the data and to reorganize themselves. At this stage, they have feeling of anger, guilt, and they might blame the educational system, that is accused for causing the difficulties. There is no doubt that the child learning environment has a great impact on a child's overall functioning learning, but the education system does not have direct responsibility for the existence of L.D. The child arrives to the education system with learning difficulty, and the system is supposed to provide an appropriate program for making learning easier. Some parents deny the L.D diagnosis results and refuse to accept it.

Family stress can be also produced from imbalance between the school's demands from the family, and the family's ability to meet those demands. These demands are commonly referred to as stressors. Durban et al. (2012) researched the issue of parents coping, and they found that $65 \%$ of parents had

${ }^{28}$ E.M. Cummings, A.L. Greene, K.H. Karraker, Life-span developmental psychology: Perspectives on stress and coping, Psychology Press, 2014; R.S. Lazarus, S. Folkman, Coping and adaptation, [in:] The handbook of behavioral medicine, Ed. W.D. Gentry, New York 1984.

${ }^{29}$ J.A. Romas, M. Sharma, Practical stress management, 2nd edition, Needham Heights, MA 2000. 
stress when they were announced about the finding of their child disability. ${ }^{30}$ This results are reinforced by the study of: Fiedler Simpson \& Clark (2007). ${ }^{31}$

The main burden of family stress can originate from the family itself, or outside of the family as an environmental stress factor. In a state of stress, family stress interferes with family daily activity, the family loses her balance and that disrupts it to function as a complete system. The stress embraces all family members that composite from subunits, and each one affects the other. To sum up the effects of the stress on the family, Dyson (2010) claims that the presence of a child with L.D within a family, bring with it stress that have some positive and negative effects. ${ }^{32}$ The positive effect is the fact that as a result of living with a child with L.D, sibling has developed intellectually and socially, they are better educated and have greater tolerance of differences. Negative effects are parental feeling of guilt and family stress. Cultural factors has a great impact on the family coping ways. Every family is different in terms of character. It is important to understand the parents coping mechanisms, and what motivates them and also to explore how to cope with a child with special needs.

In order to deal more effectively with the specific difficulties of L.D and associated difficulties. The parents first step is to learn more about the essence of the L.D and what the appropriate interventions are. The parents are looking for books and articles and participate in lectures expanding their knowledge and understanding of the LD subject. Pain, (1999) claims that the search for sources of information and advice about the child's L.D can help the parents to receive support in order to improve child care, to help them cope emotionally with the existing situation, and to know what and where they can get help. ${ }^{33}$ In the next stage, when the parents are beginning to understand their child disability at this point, there is great importance to the resilience of the parents. Resilience is the ability to withstand crises and distress. It allows families to actively cope with stress, and it shows optimism, boast the condition of the child, getting help support factors, faith and communicate with extended family.

Heiman (2002) indicated three main factors that help parents cope and recover. ${ }^{34}$ A. Free and open discussion of family members, friends and profes-

30 J.M. Durban et al., Coping strategies of parents of children with development delay: A quantities analysis, Asian Journal of Social Sciences and Humanities, 2012, 1(4).

31 C.R. Fiedler, R.L. Simpson, D.M. Clark, Parents and families of children with disabilities: Effective school-based support services, Prentice Hall, 2007.

32 L. Dyson, Unanticipated effects of children.

${ }^{33} \mathrm{H}$. Pain, Coping with a child with disabilities from the parents' perspective: the function of information, Child: Care, Health and Development, 1999, 25(4).

${ }^{34}$ T. Heiman, Parents of children with disabilities: Resilience, coping, and future expectations, Journal of Developmental and Physical Disabilities, 2002, 14(2). 
sionals and flow of information regarding the situation of the child. B. A positive relationship between the parents C. Psychological and social support to the family; and positive thinking regarding - coping and trust in the ability of the child.

As it can be seen in the literature, the parents response of stress situation, involved handling a child with a learning disability, depends on various factors such as the degree of their perception of the situation; ${ }^{35}$ characteristics of their personality, state of SES, level of education, social support and more. ${ }^{36}$

\section{Parents's ways of coping - a cultural aspect}

Cultural diversity bring along situation where the parents are going through bi-cultural socialization process: First, the private (family) system and the second, in the public (school)system. Their children are exposed to different socialization agents that emphasize different goals and ways of socialization. As this study focuses primarily on sociological factors,

Sometimes misunderstanding is created between schools and the families of immigrant children with learning disabilities due to cultural differences, and it may harm the child, because parents play a critical role in upbringing of these children. Therefore, legitimization of cultural identity, socialization goals and practices of different cultures, is a crucial factor in child development. ${ }^{37}$

Parents can be perceived in different cultures and being accused of abuse and neglect in dealing with their child. For example, Israel prohibited by law physical punishment for children, and it is considered as abuse. Ethiopian and former Soviet Union Parents suffered as they were referred to welfare authorities due to adopting such penalties. It is important to conduct a sociocultural context of cultural transition families, and highlight the way in which ecological change affects the goals and methods of parental socialization on various levels, particularly in extreme social passageways. Cultural differences may explain misinterpretation of parenting behaviors, and can cause a false diagnosis (such as abuse and neglect in light of cultural differences). So should parents and socialization agents understand and respect the cultural differences, between them and together find ways to bridge differences. The Israeli society, which has a complex fabric of relations between ethnic and

${ }^{35}$ R.S. Lazarus, S. Folkman, Coping and adaptation.

${ }^{36}$ T. Heiman, Parents of children with disabilities: Resilience, coping, and future expectations, Journal of Developmental and Physical Disabilities, 2002, 14(2); L. Dyson, Unanticipated effects of children with learning disabilities.

37 D.R. Strier, Coping strategies of immigrant parents: Directions for family therapy, Family Process, 1996, 35(3). 
religious groups, is a laboratory for research on the effects of the cultural context of child development.

The education of children from another culture is a significant difficulty for professionals and wrong treatment can cause heavy injustice to children and their families. In fact it is clear that the aspect of cultural diversity is reflected in various ways including parents' ways of coping with disability and it is difficult to present the diagnosis and identification of ways to cope parents with regard to the cultural aspect.

\section{Conclusions}

The researcher was drawing the connections between Learning disability, society and culture, attitudes, stress and coping concerning the parents of children diagnosed as having Learning Disability. There is an urgent need to explore these parents' varied cultures, their different beliefs, attitudes, and their characteristics. It is important to remember that the family is a supportive framework that protects the child. The best way to help the L.D. child and his family is through understanding and recognizing the sociological major impact on parental attitudes toward their child's learning disability that can make a difference in the perception of the educational system, and light a new angle of vision that will be offered for training the parents and the educational staff. This issue is not only a national issue, the author believe that it should be more discussed at international educational conferences, dealing with changing trends in education.

\section{BIBLIOGRAPHY}

Chandramuki S., Vranda M.N., Attitudes of parents towards children with Specific Learning Disabilities, Disability, CBR and Inclusive Development, 2012, 23(1).

Cummings E.M., Greene A.L., Karraker K.H., Life-span developmental psychology: Perspectives on stress and coping, Psychology Press, 2014.

Desforges C., Abouchaar A., The Impact of Parental Involvement, Parental Support and Family Education on Pupil Achievement and Adjustment: a Literature Review, 2003.

Durban J.M., Rodriguez-Pabayos A.M., Alontaga J.V., Dolorfino-Arreza G., Salazar C., Coping strategies of parents of children with development delay: A quantities analysis, Asian Journal of Social Sciences and Humanities, 2012, 1(4).

Dyson L.L., The experiences of families of children with learning disabilities: Parental stress, family functioning, and sibling self-concept, Journal of Learning Disabilities, 1996, 29(3).

Dyson L., Unanticipated effects of children with learning disabilities on their families, Learning Disability Quarterly, 2010, 33(1).

Eagly A.H., Chaiken S., The Psychology of Attitudes, Fort Worth, TX: Harcourt Brace Jovanovich, 1993. 
Fiedler C.R., Simpson R.L., Clark D.M., Parents and families of children with disabilities: Effective school-based support services, Prentice Hall, 2007.

Gonen-Avital S., Cultural Diversity and its implication on parents' attitudes toward their child, Learning Disability, 2016.

Grolnick W.S., Ryan R.M., Self-Perceptions, Motivation, and Adjustment in Children with Learning Disabilities a Multiple Group Comparison Study, Journal of Learning Disabilities, 1990, 23(3).

Heiman T., Parents of children with disabilities: Resilience, coping, and future expectations, Journal of Developmental and Physical Disabilities, 2002, 14(2).

Heiman T., Berger O., Parents of children with Asperger syndrome or with learning disabilities: Family environment and social support, Research in Developmental Disabilities, 2008, 29(4).

Hofstede G., Culture's consequences: Comparing values, behaviors, institutions and organizations across nations, Sage Publications, 2003.

Hofstede G., Dimensionalizing cultures: The Hofstede model in context, Online Readings in Psychology and Culture, 2011, 2(1), 8.

Lazarus R.S., Folkman S., Coping and adaptation, [in:] The handbook of behavioral medicine, Ed. W.D. Gentry, Guilford, New York 1984.

Lifshitz C., Noam G., Habib J., The Absorption of Ethiopian Immigrant Youth: A Multi-Dimensional Perspective (Summary Report), JDCBrookdale Institute, Jerusalem 1998.

Margalit M., Heiman T., Family climate and anxiety in families with learning disabled boys, Journal of the American Academy of Child Psychiatry, 1986, 25(6).

Pain H., Coping with a child with disabilities from the parents' perspective: the function of information, Child: Care, Health and Development, 1999, 25(4).

Philipchalk R.P., Invitation to social psychology, Harcourt Brace College Publishers, 1995.

Romas J.A., Sharma M., Practical stress management, 2nd edition, Allyn \& Bacon, Needham Heights, MA 2000.

Stone W.L., La Greca A.M., The social status of children with learning disabilities: A reexamination, Journal of Learning Disabilities, 1990, 23(1).

Strier D.R., Coping strategies of immigrant parents: Directions for family therapy, Family Process, 1996, 35(3). 